\title{
Qualitative characteristics of blood meal and feather meal in connection with the possibility of its use in fish feed
}

\author{
Sergei V. Beketov*, Alexander V. Kozlov, Dmitry L. Nikiforov-Nikishin, and Artem M. Platonov \\ K.G. Razumovsky Moscow State University of Technologies and Management (the First Cossack University), 109004 Moscow, Russia
}

\begin{abstract}
The article considers the groundlessness of the analysis of free fatty acids in dry animal feed through the example of blood meal and feather meal. The joint use of methods for determining ammonia and total volatile nitrogen to assess the degree of hydrolysis of feather meal used in aquaculture is proposed.
\end{abstract}

\section{Introduction}

Aquaculture has developed rapidly in recent decades. For example, in 2016, with global fish production of 171 million tons (production and cultivation), aquaculture provided 80 million tons or $46.8 \%$ of the total volume [1]. Since the 50 s of the last century, the active use of fish meal in aquaculture began, the needs for which, taking into account the intensive development of the industry at first, increased annually by an average of $8.8 \%[2,3]$.

Suffice it to say that according to 2015 data, the world aquaculture used $70 \%$ of all fish meal produced and its consumption in this segment significantly prevails in comparison with other branches of agricultural production (pig $-22 \%$, poultry $-6 \%$ and other $-2 \%$ [1].

Fish meal is a valuable source of high-quality protein, the content of which ranges from 60 to $70 \%$. Fish meal protein is characterized by high levels of methionine, cystine, lysine, threonine and tryptophan and amino acid composition is close to the protein of chicken egg.

At the same time, fish meal is the most expensive component of feed used in fish farming, which greatly hinders the further development of the industry. Therefore, the reduction of dependence on fish meal through the use of new sources of protein in fish feed is recognized as one of the main ways of further development of aquaculture [4].

Poultry and livestock by-products such as poultry meat flour, feather and blood meal are important sources of protein for use in feeding fish. They contain basic amino acids, vitamins and minerals, and unlike plant proteins are virtually free of anti-nutrients. However, in connection with this question the qualitative characteristics of dry feed of animal origin. With special interest for aquaculture is the future of hydrolyzed feather meal, as they have better digestibility and absorption.

\section{Materials and methods}

The objects of our study were samples of blood, feather and hydrolyzed feather flour. The quality of feed was determined by the content of total volatile nitrogen (TVN) [5, 6], free fatty acids (FFA) [5], ammonia [7], as well as free amino acids, which were determined by the method developed by specialists of GC "Lumex" [8], adapted by us for the capillary electrophoresis system Beckman Coulter. Statistical data processing was performed using Microsoft Excel and STATISTICA.

\section{Results}

Among the laboratory methods of sanitary and chemical assessment of the quality of animal feed protein, the most widespread were the determination of total volatile nitrogen (TVN) and free fatty acids (FFA). According to the results of the analysis of 21 samples of blood meal, the calculation of the main parameters of variability in them of total volatile nitrogen (TVN) and free fatty acids (FFA) was carried out (Table 1). It is known that the greater the value of the coefficient of variation $(\mathrm{CV})$, the less homogeneous the data. In our example, when comparing two indicators of sanitary and chemical quality of feed, in contrast to the FFA, the TVN level is somewhat more uniform. The value of the coefficient of variation of TVN was $85.96 \%$, while the FFA for the same period of time is defined as too heterogeneous data set $C V=107.00 \%$, which may indicate the use of preservatives in the production of blood meal.

In other words, at the stage of preservation of feed artificially creates a sufficiently high background level of volatile fatty acids, which distorts the real picture of their actual content and requires rethinking the use of the indicator for assessing the sanitary and chemical quality of feed.

Since the process of proteolytic activity of bacteria occurs simultaneously with the formation of TVN and 
FFA, we tried to establish whether there is a correlation between these two indicators. In order to do this, the data were combined and normalized by homogeneity. Graphical results of regression analysis of blood meal are shown in Figure 1.

Table 1. The TVN and FFA level in samples of blood meal

\begin{tabular}{|c|c|c|c|c|}
\hline \multirow{2}{*}{ Indicator } & \multicolumn{4}{|c|}{ Blood meal } \\
\cline { 2 - 5 } & $\mathrm{n}$ & $\begin{array}{c}\text { Mean+Std. } \\
\text { Error }\end{array}$ & $\begin{array}{c}\text { Std. } \\
\text { Dev. }\end{array}$ & $\begin{array}{c}\text { Coef. } \\
\text { Var. }\end{array}$ \\
\hline TVN, mg 100 g & 21 & $186.24+34.93$ & 160.08 & 85.96 \\
\hline $\begin{array}{c}\text { FFA, } \mathrm{mg} \mathrm{KOH}_{100 \mathrm{~g} \mathrm{~g}^{-1}} \\
\text { Tyyyy}\end{array}$ & 21 & $530.80+123.94$ & 567.96 & 107.0 \\
\hline
\end{tabular}

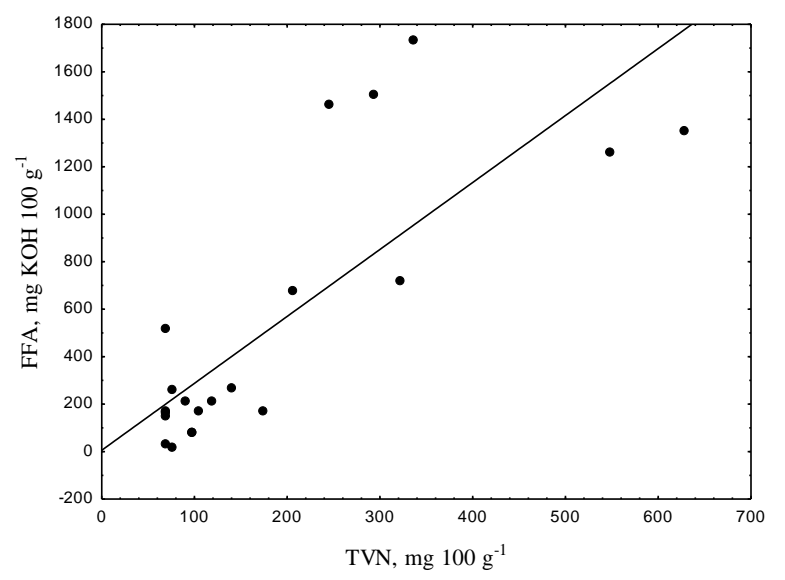

Fig. 1. Graph of the regression equation $y=5.5323+2.8204 x$, reflecting the relationship between the level of TVN ( $\mathrm{mg} 100$ g-1) and FFA (mg KOH $100 \mathrm{~g}-1$ ) on the results of analysis of blood meal samples.

According to the results, there is a positive and reliable correlation coefficient between the levels of TVN and FFA. At the same time, the calculated values of the determination coefficients $\mathrm{R}_{2}=0.632$ and the value of the correlation coefficient $\mathrm{r}=0.795(\mathrm{p}<0.001)$ indicate a high strength of the relationship between the variables, i. e. the considered pair of signs moves in one direction, which can be another additional argument in favor of abandoning the use of FFA to assess the sanitary and chemical quality of feed in fish farming.

This is especially relevant for low informative value of this indicator against the background of the use of preservatives based on organic acids in feed production.

The effect of organic acids added to the feed on the value of the FFA index is clearly reflected in table 2, where the results of a model experiment are presented, during which mineral acids (37\% hydrochloric acid, $50 \%$ sulfuric acid and orthophosphoric acid) and organic (75\% acetic acid, propionic acid and formic acid) were added to the blood meal in the amount of 200 microliters per $100 \mathrm{~g}$ of blood meal.

As a result, in feed mixtures with preservatives, both mineral and organic, a constant value of the TVN level was observed in comparison with the control sample (without the addition of preservatives). However, there is a significant increase in the indicator of FFA in cases of use as a preservative agent of organic acids, which indicates the unreasonableness of the use in such cases of this indicator to assess the quality of protein feed.

Table 2. Indicators of TVN and FFA when added to the blood meal mineral and organic acids

\begin{tabular}{|c|c|c|}
\hline \multirow[t]{2}{*}{ The sample of blood meal } & \multicolumn{2}{|c|}{$\begin{array}{l}\text { The value of the indicator of } \\
\text { sanitary and chemical quality } \\
\text { of samples }\end{array}$} \\
\hline & 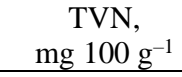 & $\begin{array}{l}\text { FFA, mg } \\
\text { KOH } 100 \mathrm{~g}^{-1}\end{array}$ \\
\hline Blood meal (BM) & 70.0 & 145.6 \\
\hline \multicolumn{3}{|c|}{ When adding mineral acids } \\
\hline BM+hydrochloric acid & 70.0 & 145.6 \\
\hline BM+sulfuric acid & 70.0 & 145.6 \\
\hline BM+orthophosphoric acid & 70.0 & 145.6 \\
\hline \multicolumn{3}{|c|}{ When adding organic acids } \\
\hline BM+ acetic acid & 70.0 & 215.0 \\
\hline $\mathrm{BM}+$ formic acid & 70.0 & 235.4 \\
\hline $\mathrm{BM}+$ propionic acid & 70.0 & 222.7 \\
\hline
\end{tabular}

The second aspect of the problem of using dry animal feed in aquaculture is the assessment of the degree of hydrolysis of feather meal. For this purpose, an effective method is to determine the free amino acids in the feed by chromatography or capillary electrophoresis, followed by the calculation of the total area of the peaks.

The corresponding results of the separation of samples of feather and hydrolyzed feather flour obtained during capillary electrophoresis are shown in Fig. 2 and 3. It can be seen that much more free amino acids are present in hydrolyzed feather flour (detected peaks after electroosmotic flow, identified at a retention time of $10 \mathrm{~min})$.

However, the implementation of this method in practice is limited by the presence of complex and expensive equipment, and therefore of particular interest is the search for more affordable and fast methods of qualitative characteristics of feed of animal origin.

For this purpose, we proposed a modification of the method for determining ammonia in an aqueous extract, which was originally developed at the NPO ZAO «Crismas + » for the analysis of meat and offal [7].

All that is required for the analysis of ammonia is: 1. the help of Nessler's reagent. 2. Distilled water. 3. Funnel. 4. Chemical glass $100 \mathrm{ml}$. 4. Tubes of transparent plastic or glass $5 \mathrm{ml}$. 5. Glass rod. 6. Paper filter "blue tape". 7. Automatic adjustable pipette or a medical dropper.

Before testing a sample of dry feed, it is necessary to prepare its aqueous extract: 1 . Place $5 \mathrm{~g}$ of dry feed in a beaker. 2. Add $20 \mathrm{ml}$ of distilled water and infuse the solution for 15 minutes, stirring it periodically with a glass rod. 3. Filter the extract through a paper filter.

To measure it is necessary: 1 . to take $1 \mathrm{ml}$ of the resulting extract into a plastic or glass tube with an automatic or glass pipette and add $160 \mu \mathrm{l}$ (10 drops) of Nessler's reagent. 2. To observe the change in color and transparency of the tube for 10-20 min. 3. To decide on the further use of fish meal. 


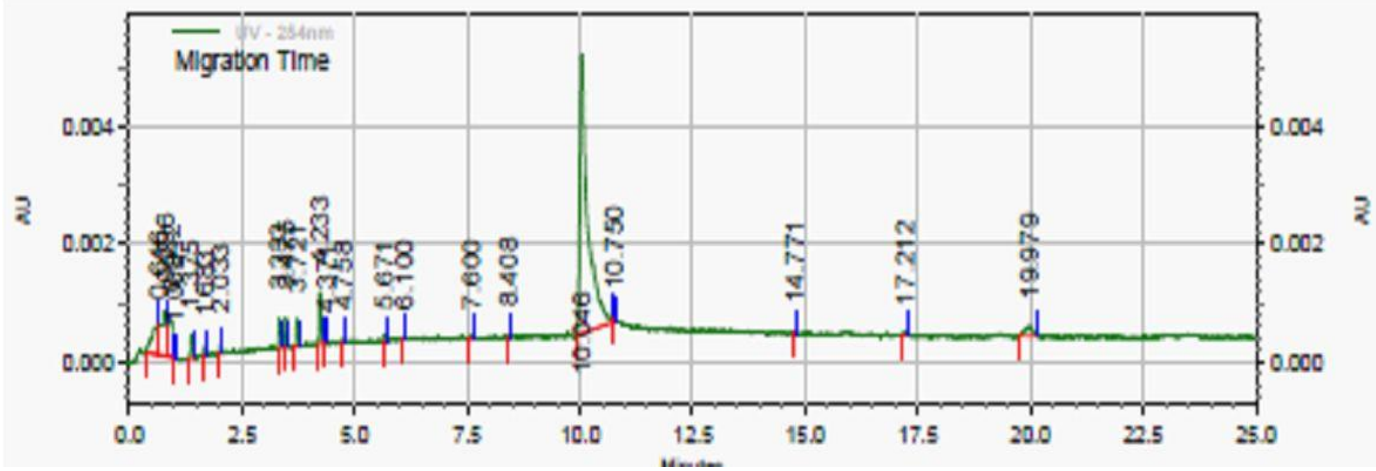

Fig. 2. Analysis of feather meal by capillary electrophoresis

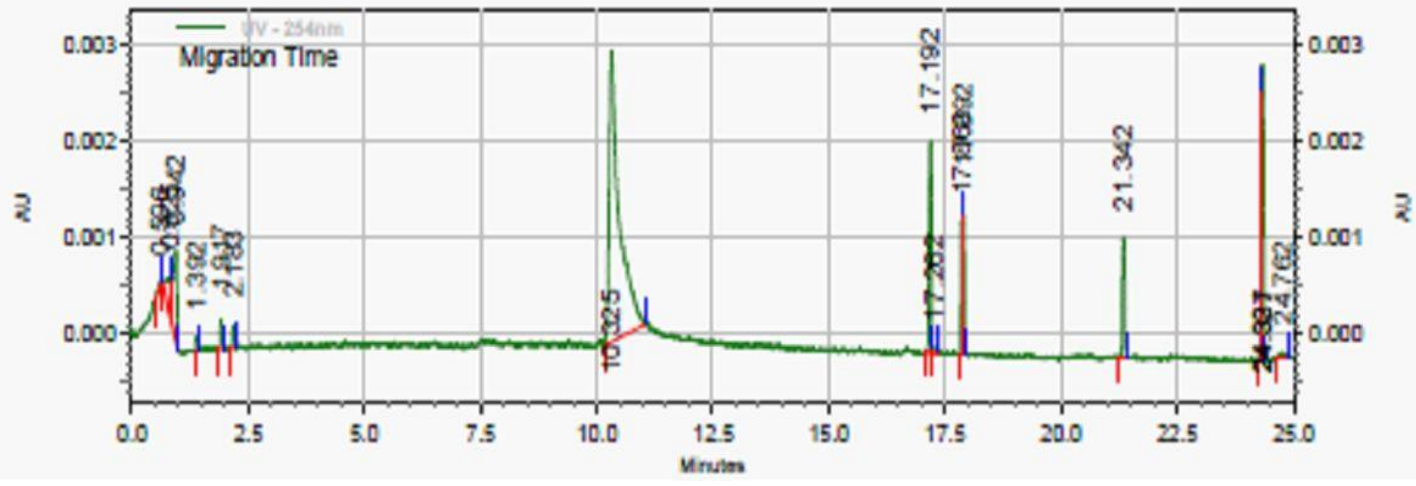

Fig. 3. Analysis of hydrolyzed feather meal by capillary electrophoresis

The essence of this approach lies in the fact that at the level of limiting values, ammonia with the Nessler's reagent forms mercuramide compounds colored in orange.

It is important to note that the Nessler's reagent gives a color reaction not only with ammonia (free and bound) and ammonia compounds, but also with amines, creatinine and some other primary products of protein breakdown, while amino acids and purine bases (structural elements of DNA ) do not participate in this reaction [9].

However in this case we are primarily interested in assessing the degree of feed hydrolysis. We supplemented the definition of ammonia by the analysis of total volatile nitrogen, which means not only nitrogen contained in amines (methylamine, dimethylamine, trimethylamine, histamine, etc.), amino alcohols, ammonia $\left(\mathrm{NH}_{3}\right)$ and its inorganic compounds, as well as in the amino group $\left(-\mathrm{NH}_{2}\right)$ monoaminocarboxylic amino acids [7, 9].

Further, the authors consider the same food samples: feather meal and hydrolyzed feather meal, examining them using the ammonia analysis method (color reaction). Both samples turned out to be of poor quality (orange color of the extract), i.e., with high ammonia content.

However, according to the results of the subsequent analysis of total volatile nitrogen, the following results were obtained: feather meal - $133 \mathrm{mg} 100 \mathrm{~g}^{-1}$ and hydrolyzed feather meal - $329 \mathrm{mg} 100 \mathrm{~g}^{-1}$. Accordingly, an increased TVN level in the feather hydrolyzate compared to feather meal indicates an increase in the concentration of free amino acids in it, which confirms the data obtained during the analysis of these samples by capillary electrophoresis.

Similar results are also obtained when conducting a model experiment. When methionine was added to a weighed feed (feather meal) at a ratio of 9:1 the TVN level increased from 93 to $527 \mathrm{mg} 100 \mathrm{~g}^{-1}$. Moreover, in both samples, the reaction to ammonia gave a yellow color, which indicates good quality for this indicator (Table 3).

Animal by-products such as feather meal, poultry meat meal and blood meal are important sources of protein for use in fish feed. They contain essential amino acids, vitamins and minerals and, unlike plant proteins, are virtually free from anti-nutritional properties.

Table 3. Comparable measurements of ammonia and TVN levels in a control sample of feather meal and with the addition of methionine

\begin{tabular}{|c|c|c|}
\hline Sample & $\begin{array}{c}\text { Measurement } \\
\text { parameters }\end{array}$ & $\begin{array}{c}\text { Ammonia and } \\
\text { TVN level }\end{array}$ \\
\hline \multirow{2}{*}{ Feather meal } & ammonia (color) & yellow \\
\cline { 2 - 3 } & TVN, mg $100 \mathrm{~g}^{-1}$ & 93 \\
\hline \multirow{2}{*}{$\begin{array}{c}\text { Feather meal }+ \\
\text { methionine }\end{array}$} & ammonia (color) & yellow \\
\cline { 2 - 3 } & TVN, mg $100 \mathrm{~g}^{-1}$ & 527 \\
\hline
\end{tabular}

\section{Discussion}

Feed costs are one of the most expensive costs in aquaculture and account for up to $70 \%$ of the cost of fish. The ways of a possible solution to this problem 
include the inclusion of more economical alternative ingredients in the composition of feed for fish. In addition, the use of feed obtained as by-products of poultry and livestock will reduce the pressure on fisheries to provide feed for aquaculture. In this connection, an effective assessment of the quality of feed partially replacing fish meal is required. Thus, at present, the need for the method of determination of volatile fatty acids is being reconsidered. For example, more and more often this indicator is absent in quality certificates for sold dry food, including fish meal.

Indeed, the increased content of FFA, often observed in fish meal, blood meal, feather meal is a consequence of the widespread use of organic acids and their salts as preservatives. According to the company ADDCONGroup pretreatment of fresh fish preservative based on formic acid (potassium formate) compared to untreated allows 48 hours of storage by $29.2 \%$ to reduce the level of TVN and almost 3 the amount of histamine, with an average of $2.8 \%$ increased yield of dry matter, which is essential in the production of fish meal [10].

Therefore, under the circumstances, it is total volatile nitrogen that most adequately reflects the degree of disintegration of the protein of animal feed, which is confirmed by our studies. Our proposed methodological approach will accelerate the decision on the use of hydrolysates of feather meal in fish feed and optimize the diet based on fish meal with a decrease in its cost.

It is important to note that the proposed methods for assessing the qualitative characteristics of blood and feather flour can also be used to identify counterfeits.

Most often, for this purpose, some unscrupulous manufacturers add inorganic nitrogen-containing compounds (urea, ammonium salts, etc.) to low-grade fish meal. In particular, the inclusion of $1 \%$ urea (carbamide) $\left(\mathrm{NH}_{2}\right)_{2} \mathrm{CO}_{3}$ or ammonium nitrate $\mathrm{NH}_{4} \mathrm{NO}_{3}$ in fishmeal increases the crude protein content in its Kjeldahl analysis by $3 \%$, but such a protein replacement is unacceptable in fish diets, as it can cause symptoms of ammonia poisoning and to prevent it, a timely chemical analysis of fish meal is necessary.

Most often, in this case, it is recommended to establish the content of raw protein and protein in fish meal according to Barnstein and calculate the amount of inorganic nitrogen-containing compounds by their difference [4].

However, a number of difficulties arise, since the determination of nitrogen by Kjeldahl is quite long in time and limited in the number of analyzed samples by the number of holes in the digester. In addition, the task is complicated if the fish meal comes in bags from different batches.

In this regard, to study the quality of fish meal protein, we propose to use our modification of the method of qualitative determination of ammonia and ammonia salts in an aqueous extract.

It should also be noted that another option for the falsification of high-quality fish meal is mixing it with little valuable or difficult to digest plant or animal components with the addition of synthetic amino acids to increase the level of crude protein.
In this case, the combination of the ammonia determination method described above (color reaction) with the actual determination of the total volatile nitrogen level will help. If the value of TVN does not correspond to the interval assessment for the detected color of the extract of the analyzed fish meal, and goes beyond the limits set for it in the direction of increase, it can be confidently argued that this sample contains either hydrolysates of animal feed or synthetic amino acids.

This is due to the fact that in addition to really harmful substances (intermediate and final products of protein breakdown) that cause various violations of physiological functions of the organism, the variability of the TVN parameter can be influenced by the presence of free amino acids and hydrolysates in the feed.

According to our data, the level of total volatile nitrogen in betaine (trimethylglycine) in its pure form is - $700 \mathrm{mg} 100 \mathrm{~g}^{-1}$, amino acid glycine - $9100 \mathrm{mg}$ $100 \mathrm{~g}^{-1}$, belcodene (partially hydrolyzed collagen) $840 \mathrm{mg} 100 \mathrm{~g}-1$, the hydrolysate of the soy $-2345 \mathrm{mg}$ $100 \mathrm{~g}^{-1}$ and the introduction of such components with the aim of falsifying fish meal will increase the level of TVN.

\section{Conclusion}

Thus, the combined use of simple and fast enough methods for determining ammonia and total volatile nitrogen can be considered not only when checking feed for toxicity by the presence of inorganic nitrogencontaining compounds in them, but also as an indirect assessment of the digestibility of feather meal used in aquaculture.

In addition, it is necessary to add that the proposed analytical approaches, of course, do not give a complete qualitative characteristic of the protein analyzed feed. However, their use allows rapid screening of a large number of samples, including the presence of toxic inorganic nitrogen-containing substances. It is also important that the considered methods are applicable in the detection of protein adulterations (exogenous inclusions of protein hydrolysates and synthetic amino acids).

\section{References}

1. R. Roubach, Must fish feeds contain fishmeal? Infofish Int. 3, 39-41 (2019)

2. FAO. The role of aquaculture in sustainable development, 34th Session (Rome, 2007) Retrieved from: http://www.aquafeed.com

3. A. Chamberlain, Fish meal and fish oil - the facts, figures, trends, and IFFO's responsible supply standard (2011) Retrieved from: http://www.iffo.net/system/files/FMFOF2011_0.pdf.

4. R.W. Hardy, Alternate protein sources for salmon and trout diets Animal Feed Science and Technology 59(1-3), 71-80 (1996) 
5. E.A. Petuhova, R.F. Bessarabova, L.D. Haleneva, O.A. Antonova, Zootechnical analysis of feeding stuffs (Kolos, Moscow, 1981)

6. GOST R 55479-2013 Meat and meat products. Methods for the determination of amino ammonia nitrogen (FGUP "Standartinform", Moscow, 2014)

7. Test Food Sanitary Guide (Krismas+, St. Petersburg, 2014)

8. N.V. Komarova, Ya.S. Kamencev, Practical guide for the use of the "KAPEL"' Capillary Electrophoresis Systems (Veda, St. Petersburg, 2006)
9. V.A. Berestov, G.S. Taranov, Laboratory methods for assessing the quality of feed in animal husbandry (Kareliya, Petrozavodsk, 1983)

10. Ch. Lückstädt, K. Kühlmann, Fresh fish for high quality fish meal. Tests prove the effect of potassium diformate on the quality of fish under tropical conditions (2015) Retrieved from: http://www.addcon.com/fileadmin/addcon/pdf/feed/ Fishform_for_sardines_Asia_Thailand_09_final_edi t.pdf 